\title{
English Language Development in a Changing South Korea
}

\author{
Chris Larsen* \\ Hankuk University of Foreign Studies, South Korea
}

*Corresponding Author: Chris Larsen, Hankuk University of Foreign Studies, South Korea

\begin{abstract}
This paper considers English language education in South Korea as a country recently grabbing the attention of the international community with the Korean Wave and increased immigration patterns. This follows the continuation of rapid socioeconomic development, along an aging society, a lowering marriage rate, and the lowest fertility rate in the world. These changes will collectively garner quantifiable impacts important at multiple levels of society. In particular, the migratory impact is changing the South Korean English language classroom as classes are becoming increasingly diverse. The long-term effect of such influences has yet to be carefully studied in the Korean context, but can be inferred from the research of Inglehart, the World Values Survey data, and a variety of statistical country data. Since demographic changes carry unintended cultural and linguistic consequences, it is important for education policy-makers, teachers, and those that deal with the rapidly changing population, to realize the impact of new student types in the traditionally homogenous classroom. As the country evolves economically and socially, so too must it transform pedagogically to provide democratic and equal access to education to all classroom members regardless of race, ethnicity, language background, or nationality. The is a new challenge for South Korea, one that has been faced in other locations around the globe and will be a future standard by which South Korean education will be judged: as either inclusive, or not. This study will provide some resources to improve teacher background knowledge for improving language instruction in the multicultural classroom and lessons that students and teachers can use to develop and heighten cross-cultural awareness.
\end{abstract}

Keywords: ELD, Culture, South Korea, Education, Immigration

\section{INTRODUCTION}

South Korea is a highly organized society with centuries of intense emphasis on education. The modern description of this is typically called Korea's "education fever", which has generally been thought of as a "preoccupation with education" in "the most exam-obsessed culture in the world" (Seth, 2002:5). Yet there is a special fascination with English that some call "a neurosis" (Kim, 2004), as an outgrowth of Korea's Confucian educational planning, culture, and politics (Ryu, 2011). Meanwhile, there has been a barely recognizable trend in foreign language learning (FLL) in the shift from language learning and teaching to that of interpretation and translation. This may indicate, as Kachru's (1982) concentric circles of language suggests, that English in Korea could slowly be moving toward the "outer circle" to enjoy a greater degree of integration into Korea's society and institutions as with countries like South Africa, India, Nigeria, the Philippines, Bangladesh, Pakistan, Malaysia, Tanzania and Kenya. This may come from either internal or external forces, however in either case the unfortunate result is that while Koreans have continued to invest billions of dollars into decades of English programs, "the quality of teaching and research has not improved very much" (Kim, Lee, 2006). This modern-day situation is made worse by three specific and interwoven elements: 1) Existing institutions and policies foster a belief among Korean students that study and education (particularly in English) are simply a means to an end, rather than ends in themselves (Jon, 2009). 2) Recent demographic changes in South Korean are altering previously homogeneous classrooms at all levels, making them more multicultural and multilingual, leading to internal conflict and tension stemming from a myriad of sources: social, cultural, racial, economic, religious, etc... 3) Not only is multicultural education a new phenomenon in South Korea, but "foreign" language educators in particular will also come from all over the world, meaning there is no established standards or assurances that teachers, Korean or otherwise, are capable of providing equal access to education in a democratic classroom using reform-minded educational strategies toward the creation of a pluralistic society. The result is that even with good intentions, institutions and educators are 
generally at best under-serving their students and at worse marginalizing and disenfranchising them. This study will make an effort to contribute to the latter two of these three issues.

As language related disciplines, such as interpretation and translation in particular, gain a greater foothold in South Korea, it is increasingly important for educators to be aware that school demographics are not what they once were. More often now, Korean students may be native English speakers learning alongside Chinese students that are native Korean speakers intermixed with Europeans, South Asians, Africans, South Americas and others with varying levels of Korean or English. Each of these students have specific educational needs regardless what language is being taught. To not recognize and provide an appropriate degree of professional service to all students equally is simply discrimination, even if it is unintended. This circumstance is further compounded by the extremely competitive student environments of both getting into a good university and eventually getting a respectable job in South Korea. Native Korean students in particular, study for a competitive advantage to be gained mostly against each other (especially regarding the College Scholastic Ability Test), which is widely thought to explain why the Republic of Korea has the highest suicide rate in the OECD and lowest happiness, especially among students. This is reinforced by the reality that Korean workers also have low happiness and job satisfaction. Yet with the expansion of the Korean economy and the so-called "Korean Wave" in full force, Korea's status as a migratory destination has overshadowed numerous such social issues. The result is that migrants, and young South Koreans alike, are often disillusioned to discover the realities in the South are not as they expected: being far from the distortions the media provides. They have difficulties in the available educational environments and encounter numerous 'glass-ceilings' during and after school. They often remain insecure about "foreign" languages, whether Korean, English or something else, partly because institutions and teachers continue to put the primary academic focus on non-communication-based competencies: they are also overwhelmingly products of such systems. In the end, huge investments of time and money are made by natives and newcomers to develop second or third language competencies, but the languages learned remain predominately "foreign" with little attention paid to cross-cultural competence, assimilation or integration. The implication is that these trends will keep the classroom and the society linguistically, socially, ethnically, and culturally divided to one extent or another.

Whether educators teach English, Korean, or some other language, it should be honestly stated that there are many skill and training shortcomings among teachers in South Korea in the ability to teach a multicultural or multilingual environment. Naturally, it isn't always obvious to a "language expert," for example, that other sorts of competences are essential to good pedagogy. As a result, often all the burden of responsibility falls onto the student as the "learner" while the "teacher" is the source of knowledge: a classic example of the "teacher-centered classroom," epitomizing the sort of undemocratic and classist environment still ubiquitous in classrooms today. To address this issue, teaching strategies that can enhance the effectiveness of teachers, lecturers, and professors in South Korea who teach "foreign" languages, especially where multiple languages and cultures are mediated, need to learn and integrate the concept of two-way cross-cultural competence (CCC). By the conclusion, the discussion will have included an expansion of the description of the language learning problem in South Korea and a classroom prescription for its remedy. This is partly based on the author's assumption that language fluency, especially for the purposes of interpretation and translation, is closely tied to cultural and gender awareness. Though many agree that while it is generally observable that over the decades Koreans have made progress toward developing their communication skills in many languages including English, "in the future, English education policies of Korea have to develop in the direction that can lead the communicative and cultural competence of Korean learners" (Chang, 2010). It should also be added that the increasingly multicultural nature of Korea should lead toward policy changes inclusive of more than just English. The hope is that the following content can contribute meaningful to the quality of language programs, especially for language, where the time, money and policies of recent practices, have so far only been partially successful.

\section{BACKGROUND}

Korea is changing in many ways. The Korean Wave "Hallyu" is only the most recent example of how South Korea is reaching out to the world, as they have done in various ways since the end of the Korean War. Yet in the past, coming to Korea and living full time was not so easy- a byproduct of a 
long and complex history of having uncertainty about how to deal with "foreigners." Only recently have the laws loosened and allowed Korean demographics to begin to shift. However, the unintended consequence (much to the disappointment of traditionalists) is that what it means to be Korean is also shifting. As Korean demographics change the definition (or at least meaning) of what "Korean" means also changes. Numerous books have already been written on this subject spanning history, anthropology, sociology and culture, but the area of education has received little attention because the reality never existed before. While traditional Koreans may be distantly aware of the subtle change, non-Koreans find it difficult to even understand the basics of the unique character of Korea and its people. This is important as such students become part of the multicultural fabric of the Korean classroom. This is made further complicated by the fact that there are also many kinds of Koreans: South Koreans, North Koreans, Chinese-Koreans, Japanese-Koreans, Korean-Americans, "mixed" Koreans and so forth. While those groups can be safely assigned to part of the complex and unfinished story of Korean history, interwoven with culturally specific attitudes and values that have carried the Korean people through many turbulent centuries, the non-Koreans have quite a different situation. They are inside as well as outside.

It is primarily these non-Koreans migrants that are the focus of this section's discussion as they are entering the most concentrated Korean population in the world, South Korea, at a faster rate than any time in history. Non-Koreans are now approaching 3.5\% of the total South Korean population, and many of which are trying to integrate and call Korea their home. Put simply, this will carry many unintended and unexpected consequences that are worth consideration.

Overall, this situation is a predictable outcome of Korea's rapid economic development, current low birthrate and aging population. If trends continue, the future South Korea will include a large nonnative population, most of whom will have had a "foreigner" experience of difficulties and obstacles with trying to integrate into the Korean society, if they are at all successful. Yet if they are to be part of the Korean social fabric (and they are having more children than traditional Koreans), but lack acceptance and cultural awareness, how might that transform the Korean identity? And by extension, how will the Korean culture and language possibly change? A future cosmopolitan, democratic and stable Korea will be dependent upon the political and social reaction to these demographic, cultural and linguistic changes, be they positive or negative. Educators in South Korea be they Korean or nonKorean, especially in language training, will unquestionably be part of shaping how this eventual future may manifest.

It is well known that Korea has been a rapidly changing nation for decades: full of vigor and a fire for development. Not surprisingly, with its rise to power also came the waves of globalization, influence and attention within the global community, something Korea had long been striving for. However, with its newly gained status, Korea became a desirable target for migrants due to its wealth, employment or higher quality of life. This is rather predictable considering typical patterns of migration, but staunch Korean immigration policies made it rather difficult for those migrants to enter onto the peninsula. The policies were understandable in terms of protecting the livelihood of Koreans, but also rooted in a history tattered with many ill-fated experiences with outsiders. Nonetheless, the migrant force slowly grew from the early 90's and immigration policy reform began to take hold, although with some hesitancy. Despite the reservations, the movement seemed like a very good deal to many Koreans; after all, the migrant labor force fulfilled an important role in the expansion of Korean economic growth and development. Soon, the phenomenon took a turn toward increased international marriages, which largely consisted of rural men seeking foreign brides. Although this raised a number of eyebrows, the Korean government became open to the change since it had to face the fact that South Koreans have among the lowest birthrates in the world (Figure 1) while rapidly becoming an aged society. Economically speaking, since many young Koreans today consider having children (if any) to be both cost prohibitive and a strain on their freedom, encouraging migration seemed like a natural and perhaps necessary step to maintain the Korean economy into the future. This is a byproduct of what is referred to as "the emergence of post-materialist values" (Inglehart, 2000) which is a phenomenon that occurs in world societies as they become wealthier and attempt to improve life satisfaction. There are several direct effects one can see such as the decreased fertility rate, but in South Korea indirect effects are also apparent such as the plausible integration and acceptance of non-Koreans and the inevitable change in the linguistic and cultural fabric of Korean society. Such changed may carry many profound unintended consequences. 
Korea, Rep. Fertility rate, total (births per woman)

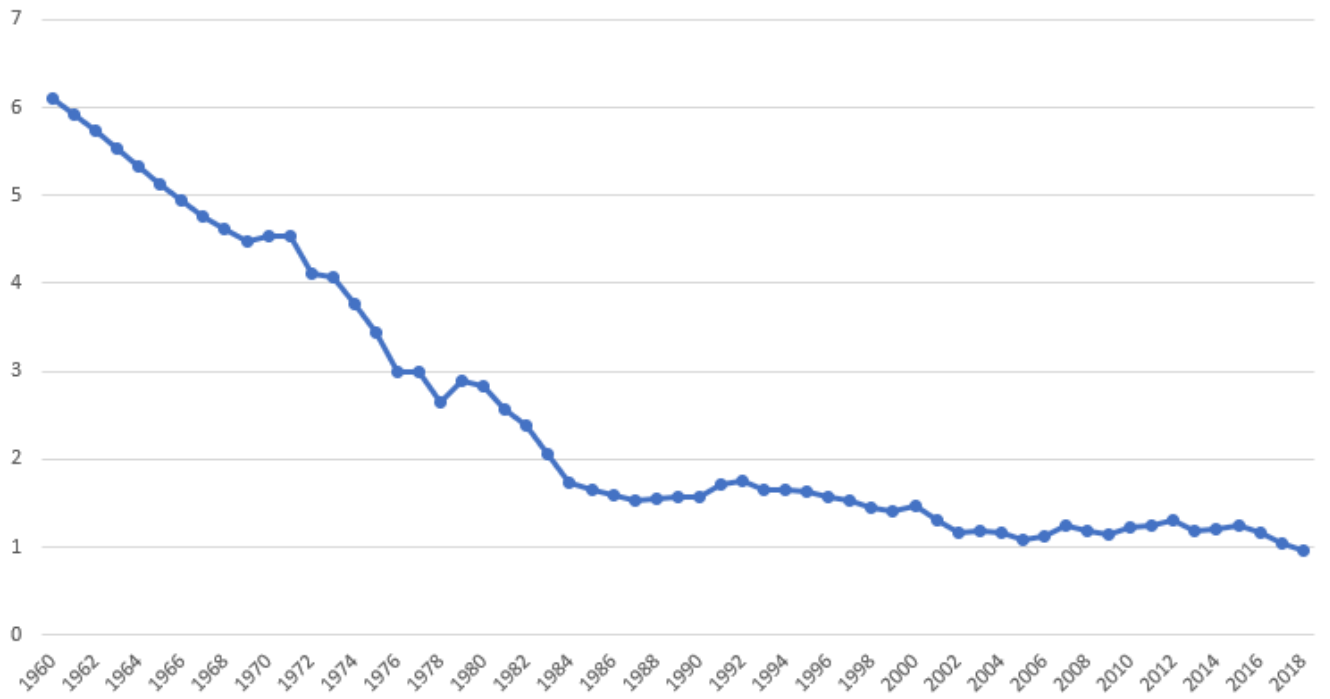

Figure1. Drop in Korean Fertility Rate

As was discussed, there is a certain logic to why South Korea is an attractive migratory destination as well as to the economic benefits for the country in the future. The numbers and trends provided by the Korean National Statistics Office and the Ministry of Justice give a fair estimation as to the foreign demographic situation in Korea. It illustrates a basic truth: The average Korean is getting older and soon the population growth of traditional Koreans will stop, while the populations of non-Koreans and "mixed" Koreans are steadily increasing. That means by 2020, the population of immigrants in South Korea will be at least $3.4 \%-4 \%$ of the total population, which naturally does not include immigrants that become Korean citizens nor the illegal immigrant population (illegal workers are difficult to track, but also on the rise. Official government reports suggest among Chinese migrants alone there are between 200,000-700,000 undocumented individuals).

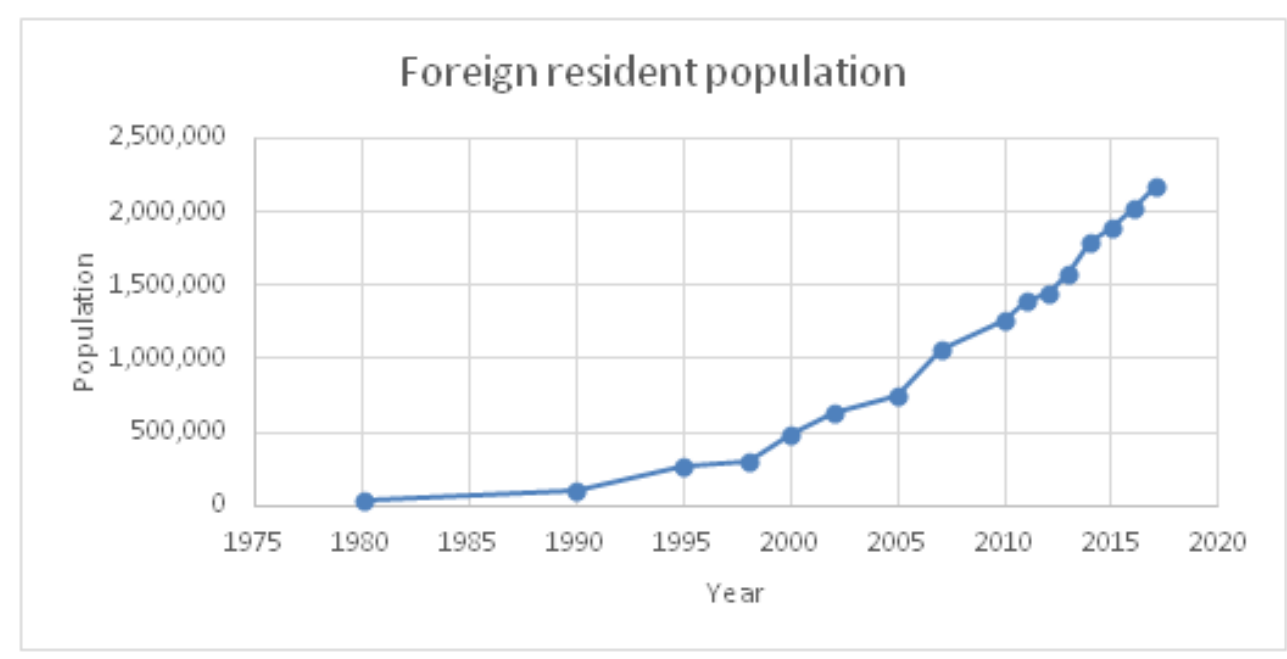

Figure2. Foreign population growth rate

While these statistics may be interesting or shocking, they are still simple trends. Policy makers may be concerned about the birthrate issue and work toward increasing Korean fertility rates. Others may perceive the above sharp demographic changes as negative or positive from a cultural or genetic point of view. Both positions are ethnocentric, whether correct or not. The issue is a sociocultural one too and the purpose here again is to illustrate the point that increased non-Korean numbers and acculturation mean the issues of integration are real and imply a major future change in the nature of being Korean, as well as to Korean language and culture. To both Koreans and non-Koreans alike this may seem strange, despite their understanding of the numbers, because in normal life there is a general sense of "us" and "them" for both groups. In culture studies this is often also called "ingroup" vs. "out-group." When non-Koreans face this there is often a feeling of "half-guest, halfoutsider" as they live a Korean life. Here this is referred to as, "the foreigner experience". 
For anyone that has spent enough time in Korea, they understand there is a sense of "Koreanness" that allows acceptance into the mainstream of Korean society. It also determines the degree of integration one can enjoy. Yet defining that "Koreanness" is actually quite slippery. It is rather difficult for Koreans to explain and doubly perplexing for non-Koreans. It is understandable and this has also long since been a challenge for social scientists and culture experts. The question here though is not really about discovering a concrete definition, but as to the degree non-Koreans can integrate. Clearly, this is multifaceted. On the one hand, non-Koreans must figure out what is necessary to integrate in the highcontext collective South Korean society: Korean language? Customs? Norms? Attitudes? On the other hand, the opinions of Koreans themselves regarding non-Korean integration is equally if not more important. A third point is also significant: even if all parties are willing, that doesn't necessarily mean they are easily compatible. All three are worthwhile to consider at length, but for the purposes of this study the third issue concerning compatibility will be addressed as it is an important dimension to language classrooms and education. Although highly contestable and controversial, the discussion of integration and change in the Korean identity can be meaningfully contributed to by citing the The Kohl's Continuum. Here it is implemented as a research model to 1) help non-Koreans understand Korean attitudes both old and new relative to their own and 2) help Koreans with the conceptual framework and language to explain to non-Koreans where they were (Image 1) and where they have been going (Image 2), in terms of values.

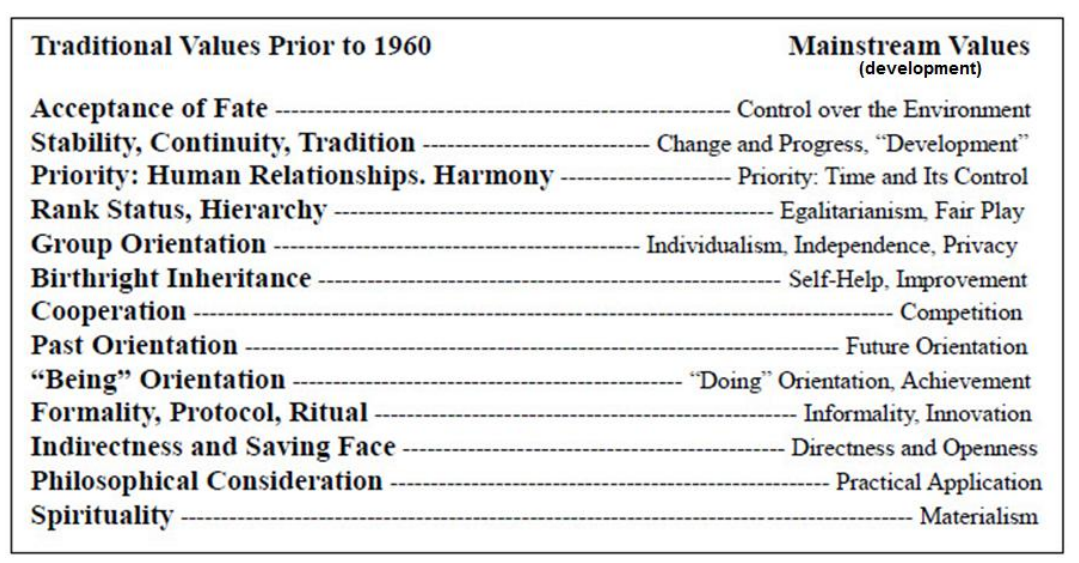

Image1. Kohl's Continuum and Pre-Development Korean Values

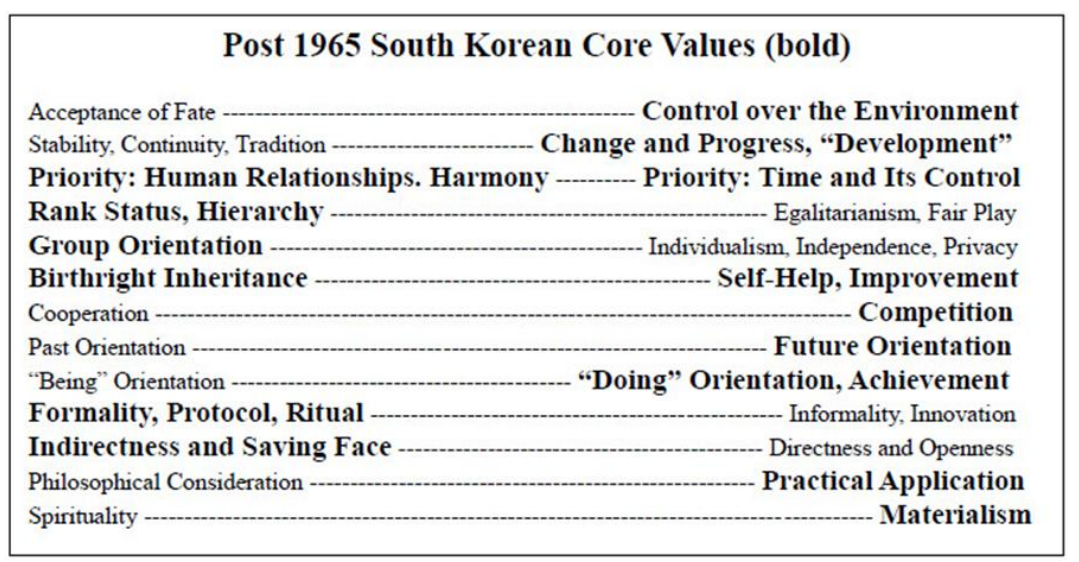

\section{Image2. Kohl's Continuum and Post-Materialist Values}

In a given country, like South Korea, perhaps one can change their citizenship, but that doesn't automatically mean that person is culturally, ethnically, linguistically or socially perfectly integrated into the society. Yet they are still members. Citizens as well are quite different from each other in numerous ways be they financial, educational, social or personal. That seems to suggest there are also degrees of integration, even with Koreans. So then, among the numerous possibilities that might explain the feasibility of non-Korean integration into South Korea, the above figures strongly implicate one in particular: a confluence of values, particularly post-materialist ones.

Values are the precursor to attitudes, and perhaps they may be defined on individual, cultural or universal terms, but it is those values that shape one's position towards life. And of course, values, 
attitudes and can beliefs change, but typically over a long timeline and subject to a myriad of variables. The Korean case in particular demonstrates that the unique imprints for Koreanness remaining after Japanese colonial occupation, and the geopolitical circumstances of the Korean War, left Korea in a position to sharply redefine itself. The subsequent years of change and development toward industrialization and democracy have had the effect of shifting Korea from one set of traditional values, to a post-modern combination of old and new. And it is still going on. It also just so happens that mosaic has a lot in common with the values systems of non-Korean migrants coming to South Korea, like the Chinese (in sharing Confucianism and a rise toward development), the "Western" (with democratization and industrialism), and others that also experienced colonialization or were recently agrarian. Taken together, this points to the fact that in a globalized age, Korean postmaterialist values are highly compatible with a large segment of the population of migrants entering Korea. And once again, even though the conditions appear sufficient, the questions of choosing or being allowed to integrate are different points entirely.

\section{COSMOPOLITAN KOREA}

Recently issues relating to multiculturalism have come under extreme scrutiny in both Europe and the United States, especially in the aftermath of the recent global financial crisis. One of the key discussion points has revolved around economic issues and social stability. For Korea, economic growth and development has been at the forefront of policy-making, but the long-term consequences have not been under particularly careful review since it proved it has had the ability to adapt and excel in the market, so there wasn't much need. Korea made a progressive shift in values conducive to economic growth but has not yet seen the need to evaluate the immigration policies it is using to curb economic stagnation from an aging population and low fertility rate. It is also important to remember that individuals as well as countries are the are the sums of their experiences and values, not just economic success. As Korea continues to change amid globalization, it must realize that demographic and value changes are also altering the fabric of Korean society and identity: Perhaps not in name, but in form. Koreans will still be Koreans decades from now, but can they be immigrants the way they are in Europe or the US? And while the phenomenon is not new South Korea, it is occurring more rapidly. As a nation, it has been part of a roller coaster of identity conversion, but over hundreds of years: especially the last hundred. Koreans showed they were resilient in the first fifty years as it was beset with some of the worst a nation can experience, including oppression and war. The last fifty years has been marked by Korea's industrial excellence, socioeconomic development, and inroads toward democratic reform. But history will likely show the last twenty years as the beginning of a cosmopolitan and multicultural Korea. How Korea responds to this will be a significant determiner of its future.

Although it may seem like overstatement to think of a future Korea as multicultural and cosmopolitan, but that is due mainly to the facts that 1) a large section of the South Korean population isn't exposed to the hundreds of thousands of non-Koreans living beside them and 2) The in-group vs. out-group issue: non-Koreans have difficulty integrating, even though they share the values to do so. The statistics discussed in this paper demonstrate that in these areas of Korean life, change is coming rapidly. The demographic shift will also shift Korean values further away from their traditional past, and the resulting population created out of increased migration and further economic development will rapidly make Korea both multicultural. As for cosmopolitanism, that will depend on the degree of integration that is allowed to occur by policy-makers and the citizenry. In either case, the culture will evolve and with it so will the Korean identity from the genetics of people to the meaning of words.

\section{Language Acquisition and Cross-Cultural Communication}

The language classroom, as well as in South Korea generally, is confronting the need to teach the nonKorean population. Of course, there are certain needs such students have at studies below the university level, but for this discussion the focus is on undergraduate, graduate, and institutional or professional learning environments. The contention here is that both Korean and non-Korean students in the classroom should have an equal access to education. That does not mean they have equal time with the instructor or something similar. Equal access implies that differing primary languages make it more or less difficult for students to access and understand course materials, instructor lectures, theories, and so forth. In the case of the Korean classroom, overwhelmingly the largely homogeneous domestic population has had the greater advantage in "access" over minorities. Being sensitive to this reality makes a big difference in the learning experience of students. 
Consider the concept of "culture". This term is almost universally translated and interpreted with oneto-one correspondence in South Korea without much questioning of accuracy. Yet to many nonKoreans in the language classroom the Korean definition may seem rather limiting: One English study compiled a list of 164 definitions of culture (Kroeber, Kluckholn, 1952). Daily students are bombarded with "culture" in their modern lives as students inside the Korean "Wave", yet quickly the terminology loses meaning for everyone: exactly the opposite of what instructors are trying to create in the classroom. It is essential that students begin to consider meaning cross-culturally. What follows are 11 lessons for diverse language classrooms to foster cross-cultural competence in students.

\section{RESUltS AND DisCUSSION}

\subsection{Lesson 1: Icebergs and Meaning}

When people express themselves, they are not only communicating from a unique cultural and individual perspective, but they are also using their languages often in inaccurate and flexible ways depending on the social context. The culture scholar Edward Hall discussed this widely used concept as "Iceberg Theory" to describe the facets of an individual or culture that are overt versus those that are hidden (Hall, 1976). Teachers and students must realize that they have both conscious and subconscious thinking patterns that impact how they think and behave. This may be as superficial as fashion, but it can also manifest as deeply rooted and unconscious prejudice or bias. That is absolutely not to imply that people from different cultures or ethnicities are somehow hard-wired differently the way an infant can recognize face as different from other objects (Nelson, 2001). Such is not the same as learning other languages or cultures. The lesson is that both of these concepts are useful to the interpreter/translator because they reflect a central concept: There is always more than what is seen, there is much beneath the surface of both words and behaviors, which also vary from culture to culture. Teachers must therefore realize that, as with all humans, they have fundamental biases about their own language, culture, and race as well as how they view individual students. Furthermore, that what one says, and means is not always understood by all the classroom members in the way it was intended. This doesn't mean that people are lying, but rather that the majority of mental processes are subconscious, nonetheless influence thinking, feeling and behavior. Children grow up with certain families, in certain cultures, which carry certain biases and predispositions. For the language teacher and student, this means being aware of what is being said, as well as not said. It means cautioning against their own ways of thinking that might taint an interpretation or translation, or lesson. It means stopping to consider.

\subsection{Lesson 2: Values and Behavior}

Teachers and students, of course, have no trouble understanding that there are different values and beliefs in Korea and in the world, but when confronted with the question "why?" it leaves them a bit perplexed. This lesson is designed to provide teachers and students a framework for understanding values and behaviors. The first is "know thyself". Teachers, however much they may succeed or fail, are expected to know who they are: at least society hopes so. However, one's perspective on the world and others is altered by formative experiences like as well as the unconscious mind. Such so called "tinted lenses" where what is seen may be identical to all observers, while what is perceived (or understood) may be different. For example, when the Korean student uses the word "individualism" in either English or Korean, there is a very slight negative connotation, which when a non-Korean hears the first student then impression of what was said might be somewhat positive. This lesson is especially important for those that liaise between cultures: to be especially aware of who, or perhaps what, they are.

\subsection{Lesson 3: Universal, Cultural or Particular}

Although students may use definitions that are inaccurate in a given situation, that doesn't mean they are always wrong. From the point of view of the teacher, especially in language usage an attempt may be wrong, but it is important to support this effort. However, this is not trial and error. Language learners will never become fluent unless they are able to tether target language concepts to source language meaning. Students need to clearly establish the frame of reference the source content is coming from and adjust. Therefore, understanding the significance of context is paramount. This is emotionally vexing however because many students tend to be preoccupied with "getting the correct answer," as a byproduct of their schooling and exam-taking. To help the students come to terms with 
this possible hang-up, it may be useful to integrate some of the many lessons available to introduce the ideas of differences among individuals. This can not only greatly help students learn more about themselves and others, but the result is that they are more in tune with the various predispositions people may have. By providing students lists of behaviors like "singing" (universal), "eating with chopsticks" (cultural), or "disliking oranges" (personal), one can get a starting idea of how much students can distinguish. At the higher levels of evaluation this becomes exceedingly difficult for students from polychromatic, high-context and collective societies like those of Korea due to a combination of strong values and a lack of background with other cultures. For example, it may seem obvious that "everyone must mourn their mother's passing away" or "isn't everyone wary of strangers?" These incorrect assumptions manifest themselves in IT rather regularly and teachers and students must be made aware of what is individual, cultural or universal if they expect to be effective in IT.

\subsection{Lesson 4: The Self and Others}

How an individual perceives oneself in relation to other people, groups, nations, or even nature, has an important impact on cross-cultural communication as well as the process of interpretation and translation. This is quite different from simply thinking about and understanding oneself or even one's culture as discussed earlier. It is also dissimilar from recognizing how various attitudes, beliefs or behaviors can be categorized as individual, cultural or universal. Rather, when one speaks, writes or somehow engages with others, that individual's identity is expected to engage in a system governed in the loosest sense by norms, and the most concrete sense by laws. In other words, the Iceberg theory applies not only to individuals, but also cultures, subcultures, civilizations, societies and nations. The various imprints that represent the collective memory of a particular culture, especially along the broad cultural lines that compose nation-states, create the unique and tangled set of values that make that culture unique and different from others. Typically, at first glance students think that untangling all the varying attitudes to be impossible. However, by placing each core value on a continuum the conceptualization becomes much easier to grasp. Naturally each continuum has a broad set of interpretation and translation issues that extend far beyond the scope of this paper, however for the purposes of students learning it is enough to understand the delimitations and how they might potentially impact the IT process.

\subsection{Lesson 5: Individualism vs. Collectivism}

Koreans have a generally good understanding of how Confucian ethics continue to shape the collectivist nature of their society. Even though this idea has been under regular attack by those that prefer the analytic-holistic worldview (Kim, Lim, Dindia, Burrell, 2010), the position is still firmly grounded in the literature. Regardless, the distinction should be made to students that concepts like "individual" or "collective" and the other core concepts and values pertaining to culture, are neutral. There is nothing inherently morally inferior or superior, from a philosophical point of view, about any position on the spectrum. This is important as the comparative process tends to bring about an individual's ethnocentric tendencies. Maintaining that neutrality for both teachers and students is an important aspect of recognizing and respecting alternative cultures.

\subsection{Lesson 6: Obligations}

All societies have a need for individuals to take care of themselves, but also for the community or group. The question is which has more influence on life. Students have a hard time with language expression problems in this area since the conflict often represents illogical behavior. Consider the strong Confucian virtue around which most all of Korean society functions: filial piety. It is most strongly intertwined with the duty of individuals to their parents, but not only that. Teachers and students alike have to be brought to realize that not all people have equal value in their commitment to others: parents, grandparents, friends, siblings, bosses, strangers, and so on. The non-Korean professor might say to a class, "Well, in my country we have more equality between our bosses," which implies not only a knowledge of what is better, but that one's own cultural approach is better. Similarly, the Korean teacher may say, "Well, we Koreans love our parents and want them to live with us when they are very old," which similarly implies to the non-Korean student in the classroom that they don't love their parents, or something similar. There is simply a lack of ethnorelativism about concepts like obligations, as well as many others. 


\subsection{Lesson 7: Universalism vs. Particularism}

Universalism stipulates that certain absolutes exit, across the board, in every situation. It suggests that "Although life isn't fair, the ideal of fairness is important, and thus fairness and egalitarianism should be aimed for". Particularism, on the other hand indicates that behavior is conditional, dependent upon circumstances. "No one really expects life to be fair." The discussion of universalism and particularism is useful for the multicultural classroom of students and teachers because historically South Korea had a lot of both. Koreans strongly believe in egalitarianism but maintain many hierarchies as well. Though there have been rules and laws to govern behavior, even in terms of its virtuousness, at the same time there are often exceptions to the rules depending on the situation or who is involved. As such, it may be a useful discussion for students to realize that just because a culture tends to be a certain way, there can be instances or circumstances that alter the behavior of the actors.

\subsection{Lesson 8: Direct vs. Indirect}

Obviously, directness and indirectness are easy enough to understand on the surface, but the questions students must answer is "why?" The situations described here are not unique, but that the standard behavior of a culture and how it communicates either directly or indirectly is important. Depending experience and sensitivity to various topics is useful encouragement to students who have trouble understanding this. Generally, however, the directness factor mostly comes from a desire to be polite. Recognizing the tone and register of the source, however, is crucial to being successful both culturally, and in language development. This is where "context" comes into play. Context is the amount of information needed to make sense of a situation, passage, sentence, gesture, etc... The more information needed, the higher the context. Generally speaking, English speaking countries are low in context because of their linguistic heterogeneity and interaction with many neighbors of differing cultures and races, which is relatively new in East Asia. In South Korea especially, the homogeneity of the peninsula has made the region very high in context because, for convenience, if everyone is similar there is little need to excessively detailed. A good illustration of this for Korean students is the dinner table, where there are numerous norms that are part of the Korean context: the highest/oldest person is farthest from the exit and closest to the main dish, pour alcohol with the right hand, receive with the right hand, demonstrate appropriate respect with the left hand, and so on. The example is largely about norms, which apply equally to language patterns, expressions, and mental models. The lesson is to be aware of issues related to high and low context.

\subsection{Lesson 9: High and Low Power Distance}

When a high power distance culture exists, some people have power, and some do not, just as some people are wealthy while others are not. It is generally not only a matter of achievement, but of ascription. What is significant is the degree of interaction and distance between the powerful and the less so. In high power distance contexts, those with power tend to understand their role toward subordinates and visa-versa. If the gap is great, communication or interaction between actors could be reduced to essentially zero. Meanwhile, in low power distance cultures, power and inequality are not natural. Those with power don't emphasize it and their subordinates are praised if they take responsibility. Higher degrees of communication between actors, with informality, tend to be the norm as the power distance is low. Cultures with rigid social structures and hierarchies tend to be more of the former, while more egalitarian societies fall into the latter. Korea as a culture and Korean as a language tend to have a high power distance, while the English speaking is largely of low power distance. This distinction plays an important role in the translation of titles and expressions of respect to people of higher and lower power.

\subsection{Lesson 10: High / Low Uncertainty Avoidance}

Similar to the previous example above, certain cultures want very much to avoid uncertainty (high uncertainty avoidance). They create detailed plans, schedules and laws to control life. The opposite (low uncertainty avoidance) are more comfortable with risk, chance and the unknown and feel confined by too many rules and laws. While this is rather straightforward, it applies to numerous situations that relate to high/low context. Also, as many Korean students tend to literally translate sentences without a subject such as, "eating dinner?", so it can create a great deal of uncertainty in the mind of the listener/reader due to an acceptance of vagueness, which is also a form of uncertainty. 
How a culture manages uncertainty touches upon many aspects of life from risk-taking to religion to attitudes about time. Cultivating a linguistic understanding for the spectrum of certainty in a society is an important way to help students avoid cross cultural mistakes.

\subsection{Lesson 11: Status and Control}

The last few lessons for the students to understand need the least explanation and, in particular for Korean students, represent a cultural transition from the past to the present. Many dynamic discussions and debates can arise out of the follow four topics. 1) Achieved Status: Success and position come from hard work. 2) Ascribed Status: Success and position are a birthright or perhaps related to my social network. 3) Internal Control: I am in total control of my life and destiny. 4) External Control: Something or someone controls my fate. There are several other notable and important cultural categories that can have an impact on the methodological and conceptual approaches a language teacher or student should consider. While they are not, perhaps, as central to the development of cross-cultural communication, they offer unique areas an instructor can explore to expand the perception of students since they are universal and shared by all cultures. Since all cultures recognize these categories, they are highly useful areas around which to design curriculum for crosscultural communication because all students can understand the category and communicate their own cultural perspective, thereby helping the development of other students. These universal attitudes center upon: Age, Fate, Human Nature, Change, Risk-Taking, Misfortune, Face/Harmony, SelfWorth, Equality, Formality, Realism, Taking Action, and Nature.

The careful individual should be able to deduce that these categories are directly or indirectly related to the central course content. For example, an individual's attitude about 'age' is closely connected to the hierarchical nature of a society, its power distance, and the potential social obligations one may have for the old or young. Also, one's perception of 'fate' and 'change' are closely linked to internal and external controls. Face also associates to high/low contexts, self-worth to achieved/ascribed status, and so on. Studying and clarifying these lessons and categories may seem external to the language learning process, but for the advancing language student, it is important to understand that culture difference extend well beyond the linguistic. Further, it is essentially impossible to be multilingual without an awareness of the cultural dynamics in play in the target language, which is what this article as emphasized for South Korean classrooms.

\section{CONCLuSion}

The purpose of this article was to give a background on the unique and changing situation of Korean multicultural language education in South Korea; primarily to offer up some useful content toward the teaching of culture theory to students in diverse classrooms, mostly for English language and interpretation and translation students in diverse classrooms. This is because the South Korean development story includes perceptions of globalization and modernization closely linked to education yet "it has been repeatedly pointed out that the quality of major Korean universities is not in par with top universities in the world" (Kim, Lee, 2006). Korean parents are likely aware of this and continue to invest a large portion of their income on education (half of which is for English), which is seen as the best tactic to achieve upward social mobility and economic prosperity in the belief that emphasizing or imposing education can lead their children to success. However, despite this emphasis on education and a propensity for taking exams, the average TOEFL scores for South Korean examinees (2005/6) ranked 93rd out of 147 countries (Park, 2009).

This paper considers that part of the problem of teaching and learning "foreign" languages in Korea is primarily rooted in the lack of cultural competences in cross-cultural communication. Yet as was discussed, the demographic changes in Korea are creating an even greater need to for multicultural education in Korea. To truly become a first world "global" society and democratic model, Korea should encourage student intercultural learning with multicultural education techniques. Constructing a truly cosmopolitan society with fluent speakers doesn't require studying abroad for a few months or years where one may face marginalization (Lee, 2006), but rather to be continuously exposed to varying beliefs and different cultures even within Korea, which can best be found in language classrooms and with competent instruction. Once students and teachers, in their own roles, expand how they personally identify with other people and cultures, they can then integrate it into their own cultural functionality (Erickson, 1968). In other words, teachers and students need to be open to identify with students and teachers from other cultures using other languages. Language students are 
an ideal starting point for this change in thinking and teaching as they 1) often represent the upper-end of cross-cultural and language ability in South Korea, 2) they are increasingly diverse and are by definition in need of cross-cultural communication, and 3) are already often made up of teachers and students from various countries and cultures. Implementing these lessons would do well to expand the concept of what is called, 'internationalization at home' (Jon, 2009), by integrating the record high numbers of international students that are coming to Korea. And in so doing, programs can begin "internationalizing," which has been proven important for curriculum development (Leask 2007; Otten 2003; Paige 1983; Stier 2003; Wächter 2003).

In sum, "Translation is an act of creation and a dynamic, ongoing process, but can also be used to reveal presumptions and biases" (McClean, 2007). Such presumptions and biases are rooted in language and perception, whether among students, teachers or policymakers. It is the job of educators in Korean English language training programs to foster the student ability to maneuver between source and target languages with precision and accuracy: correctness also implies they do so with cultural sensitivity and awareness. This is increasingly difficult from a pedagogical perspective when class diversity increases, as is increasingly the case in South Korean, in addition to the variance in abilities, languages, and cultural limitations of the students and teachers involved. By simply challenging one's pedagogical methods and learning strategies used in diverse Korean English language learning classrooms, students can improve significantly via the use of culture studies to expand self-knowledge as well as awareness and sensitivity to other cultures and languages toward a more inclusive and cosmopolitan classroom and society in South Korea.

\section{REFERENCES}

[1] Chang, B-M. Cultural Identity in Korean English. Journal of Pan-Pacific Association of Applied Linguistics, 14(1), 131-145, (2010).

[2] Chang, B-M. Korea's English Education Policy Innovations to Lead the Nation into the Globalized World. Journal of Pan-Pacific Association of Applied Linguistics, 13(1), 83-97, (2010).

[3] Erickson, E. H. Identity: Youth and crisis. New York: W. W. Norton \& Company, 1968.

[4] Hall, E. Beyond Culture. Anchor Books. NY, New York, 1976.

[5] Hofstede, G. Culture's consequences: International differences in work-related values. Sage, 1980. Beverly Hills, CA.

[6] Inglehart, R. Globalization and Post-Modern Values. The Washington Quarterly, 23 (1), 215-228, (2000).

[7] Inglehart, R. Modernization and Postmodernization: Cultural, Economic and Political Change in 43 Societies. Princeton, NJ: Princeton University Press, 1997.

[8] Jon, J-E. 'Interculturality' in higher education as student intercultural learning and development: a case study in South Korea. Intercultural Education, 20(5), 439-449, (2009).

[9] Kim, D-Y. "No Korean, Just English": English village open at Ansan." Kukmin Ilbo, August 24, 2004.

[10] Kim, J, Lim, T, Dindia, K., \& Burrell, N. Reframing the Cultural Differences between the East and the West, Communication Studies, 61(5), 543-566, (2010).

[11] Kim, J-H. A changed context of lifelong learning under the influence of migration: South Korea. Int. Journal of Lifelong Learning, 29(2), (2010).

[12] Kim, S, Lee, J. Changing facets of Korean higher education: market competition and the role of the state. Higher Education, 52, 557-587, (2006).

[13] Kachru, B. The Other Tongue. University of Illinois Press, (1982).

[14] Kohls, R. Learning to Think Korean: A Guide to Living and Working in Korea. pg. 50-62, (2001).

[15] Korean Statistical Information Service. International Migration [statistics]. Retrieved April 10, 2011, from http://kosis.kr/eng/statisticsList/statisticsListIndex.do?menuId=M_01_01\&vwcd=MT_ETITLE\&parmTabI $\mathrm{d}=\mathrm{M} \_01 \_01 \&$ statId=2004022\&themaId=\#A31.3

[16] Kroeber, A. L., C. Kluckhohn. Culture: A Critical Review of Concepts and Definitions. Cambridge, Massachusetts, 1952.

[17] Larsen, C. A Korean Identity Conversion. Interpreting and Translation Studies. 15(1), (2011).

[18] Leask, B. Diversity on campus -an institutional approach: A case study from Australia. In Internationalisation at home: Ideas and ideals, ed. H. Teekens, 33-9. Amsterdam, The Netherlands: European Association for International Education, 2007.

[19] Lee, S. Navigating Between Cultures: A New Paradigm for Korean American Cultural Identification. Pastoral Psychology, 54(4), (2006). 
[20] Maclean, K. Translation in cross-cultural research: an example from Bolivia. Development in Practice, 17(6). 748-790, (2007).

[21] Nelson, C. The development and neural bases of face recognition. Infant and Child Development, 10(1-2), 3-18, (2001).

[22] OECD iLibrary. (2011). OECD Factbook (2010): Economic, Environmental and Social Statistics. Retrieved June 26, 2011, from http://www.oecd-ilibrary.org/economics/oecd-factbook-2010_factbook2010-en

[23] Organization for Economic Co-operation and Development. Education at a glance, 2007: OECD indicators. Paris: OECD, 2007.

[24] Organization for Economic Co-operation and Development. Education at a glance, 2012: OECD indicators. Paris: OECD, 2012.

[25] Otten, M. Intercultural learning and diversity in higher education. Journal of Studies in International Education 7, p. 12-6, (2003).

[26] Paige, R.M. Cultures in contact: On intercultural relations among American and foreign students in the United States university context. In Handbook of intercultural training, eds. D. Landis and R.W. Brislin, 102-9. New York: Pergamon, 1983.

[27] Park, J-K. 'English fever' in South Korea: its history and symptoms. English Today 97, 25(1), (2009).

[28] Ryu, K, Cervero, R. The Role of Confucian Cultural Values and Politics in Planning Educational Programs for Adults in Korea. Adult Education Quarterly, 61(2), 139-160, (2011).

[29] Seth, M. Education fever: Society, politics, and the pursuit of schooling in South Korea. Honolulu: University of Hawaii Press, 2002.

[30] Stier, J. Internationalisation, ethnic diversity and the acquisition of intercultural competencies. Intercultural Education 14, 78-1, (2003).

[31] UN World Values Survey. (1981-2008). WVS Five Wave Aggregated File 1981-2005. Retrieved June 5, 2011, from http://www.wvsevsdb.com/ wvs/WVSData.jsp

[32] US Bureau of Labor Statistics. International comparisons of GDP per capita and per employed person 17 countries, 1960-2008. Division of International Labor Comparisons, 2009.

[33] Wächter, B. An introduction: Internationalisation at home in context. Journal of Studies in International Education 7: 5-1, 2003.

\section{AUTHORS' BIOGRAPHY}

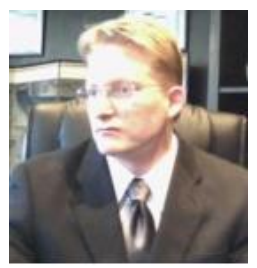

Chris Larsen teaches coursework in comparative culture, international relations, and business, at the Hankuk University of Foreign Studies in Seoul, South Korea. Dr. Larsen is an area expert on Korean culture and language with nearly twenty years teaching, writing, and presenting experience in the field. Inquiries can be directed tolarsenprof@gmail.com

Citation: Chris Larsen. "English Language Development in a Changing South Korea" International Journal on Studies in English Language and Literature (IJSELL), vol 7, no. 4, 2019, pp. 36-47. doi: http://dx.doi.org/10.20431/2347-3134.0704004.

Copyright: (C) 2019 Authors. This is an open-access article distributed under the terms of the Creative Commons Attribution License, which permits unrestricted use, distribution, and reproduction in any medium, provided the original author and source are credited. 